\title{
Discussion on the Teaching Reform Mode of Computational Method Course
}

\author{
Hao Hui ,Qiang Hongfu ,Li Xuerui ,Zhou Wei ,Wang Xueren \\ Xi'an Research Institute of High technology \\ Xi'an Research Inst. Of Hi-Tech, Hongqing Town, Xi'an, P.R. China \\ e-mail: franklinghao@163.com
}

\begin{abstract}
Computational Method course is one of professional basic courses in college of Engineering, which has strong theory and high teaching difficulty. The learning effect directly affects students' learning and research on the follow-up professional courses. By years of teaching experience and practice experience, specific reform methods had been carried out to improve the teaching effect to some extent from the aspects of the curriculum system, teaching methods and practice teaching system.
\end{abstract}

Keywords- Computational Method; Teaching Reform; Heuristic Teaching; Mathematical Modeling

Computational Method is a public basic course for engineering majors, who need the support of higher mathematics, linear algebra and provides the theory and method of numerical calculation which is very useful for the follow-up professional courses. This course belongs to applied mathematics, strong in theory, has large number of mathematical formula. Generally, students reflect that the professional courses in the most difficult course. Therefore, to the Computational Method course teacher, how to teach the theory and method for better grasp is the key point.

According to the characteristics and the teaching problems of Computational Method, with the result of students learning and feedback information, the main factor that influence the teaching effect are mainly in the following: (1) Course content is abstract, has large number of formula derivation and difficult in learning; (2) Teaching mode is simple and hard to mobilize the enthusiasm of the students; (3) Teaching and practice are disjointed; (4) Assess mechanism is poor, can not fully reflect the students' comprehensive quality. Carrying out the teaching reform is a necessary means to improve the quality of class teaching and is also an important measure to cultivate innovative talents in the new century. Therefore, according to the study in recent years, feedback information, combined with the teaching practice for several years, an effective measures of the curriculum reform is summarized here to share with colleagues.

\section{THE CONSTRUCTION OF CURRICULUM SYSTEM}

In the process of teaching reform, idea of curricula must be changed, curriculum system must be reconstituted, teaching concept must be renewed and the teaching mode must be transformed. While teaching, students should be guided to pay attention to laying a solid foundation, cultivate innovation consciousness, change study ideas, strengthen practice training, so as to establish the curriculum teaching system of taking the student as the main body, the actual problems as center, the classroom practice as means and the ability training as target to achieve the teaching objective.

\section{A. Form a complete interrelated knowledge system} structure from basic methods and basic theory of Computational Method.

Although algorithms of Computational Method are complicated, the ultimate goal of them is to obtain the approximate solutions about practical problems. In the teaching process, teachers should grasp the overall content of courses, guide students to find the difference and connection of algorithms.

B. Develop professional software suitable for Computational Method and improve practical teaching system.

In order to further the reform of curriculum and teaching, it must be emphasized on the composition of theory and practice. The teaching reform measures should be discussed with the help of analyzing the relation and gaps between them. Taking MATLAB software as an example, it provides powerful matrix calculation and simple programming method, which is very suitable for students to study and saves a lot of time for classroom teaching. As MATLAB is a standard software, it needs to be improve for Computational Method.

\section{Combine with research achievements and broad the application field of Computational Method.}

It is helpful for students to master the latest trends and development trends of the subject that the major achievements are led into the classroom teaching as one of practice content.

\section{The Reform of TeAching Methods And MeAnS}

\section{A. Match the traditional teaching with multimedia} teaching.

The traditional way of teaching is mainly explanation and writing on the blackboard, students listening and noting, which lead to the lack of intuitive feeling and dull atmosphere. Finally the students' might lose interest and enthusiasm in learning and teaching effect might be poor. The modernized teaching methods (such as multimedia and network) can free both teachers and students from boring derivation process, and can also stimulate students' interest in learning and motivation. According to the characteristics of Computational Method course, the solutions and error analyses can be explained in vivid and visual ways with the 
help of MATLAB and C language. Although multimedia courseware can improve the teachers' abuses in writing and enlarge information content, it can not be the main part in Computational Method teaching.

\section{B. Use heuristic and directed teaching methods.}

It is proved in practice that heuristic and directed teaching methods can promote students' enthusiasm, initiative and ability to think independently. In the process of teaching, teachers should guide students to find the relationship and difference among knowledge points. Before the introduction of a new algorithm, teachers should guide students to think why this algorithm was proposed and what the disadvantages of old algorithms were. These would clarify students' ideas and deepen the understanding of methods. For example, in the teaching of numerical calculus, students should be guided to improve algorithms from Newton-Coates integral formula to complex integral formula, variable step integral method and Rhomberg integral method. In addition, seasonable summary should be done to analysis the merits and faults of each algorithm as well as the scope. Heuristic and directed teaching methods can develop students' good habits to find and solve problems.

\section{Guide teaching with the idea of mathematical modeling.}

Mathematical modeling is a way to solve some practical problems with thinking of mathematics. In other words, it is a method to describe a practical problem with mathematics language, so as to establish a mathematical model. Its main idea is to help students to establish a mathematical way of thinking, with which students could clear important variables and parameters in practical problem by analysis, abstraction and simplification, and with which students could establish mutual relationship between variables and parameters by certain rules so as to obtain a mathematical model. Computational Method is a practical course. The main teaching objective is to study the basic concepts and methods of central ideas, comparing the characteristics of different algorithms, so that students could master the numerical Computational Method of all algorithms and grasp the ability to use computers to solve practical problems. For example, optimal square approximation method needs students to form basic functions with the help of rich mathematical knowledge and practical experience.

\section{The REFORM OF PRACTICE TEACHING}

In order to give students a complete and systematic mastery of the Computational Method, teaching hours should be reduced for practice such as practice teaching, extracurricular practice and extracurricular open practice. The design of practice content should be focus on how to discover and develop the potential of students, how to help students build self-confidence, how to promote students' enthusiasm. In this section, taking MATLAB or C language as platform, teachers should design different types of problems, which were closely combined with the actual. Students should produce computer programs for the solving of those problems to enlighten their thinking and broaden their horizon. These exercises not only train students' practical ability of programming, but also improve students' ability to do numerical calculation by computer. The use of a computer to complete a complete algorithm design process can deepen the students to grasp the basic principles, algorithm implementation process, calculating results and result analysis.

\section{THE REFORM OF EXAMINATION MODE}

Examination is important for evaluation of teaching. Method of examination and evaluation mechanism should reflect the integrated ability of students. The measuring of Computational Method course needs the consideration of two aspects: one is the degree of mastery to basic theory; the second is the programming ability to solve practical problem. The traditional examination mode usually adopts closed book form and judge the result by written test results only. This mode may cause the unilateral of test contents, simplex of test method and worse evaluation mechanism, which is hard to reflect the integrated ability of each student. A complete, rational, diversified examination system needs to be established to avoid the aforementioned disadvantages. In this view, the combination of written examination, practice, assignments and computer examination is developed. In this case, written examination occupies 60 percents, practice and assignments 10 percents, computer examination 30 percents.

\section{CONCLUSION}

By thinking and exploration work in teaching, combined with the actual situation of our university and students, we have gradually summarized a teaching mode for Computational Method. There are also disadvantages. In future work, the process of teaching should be continuously improved with the help of the successful experiences and learning methods from other universities to fully show the charm and characteristics of Computational Method and cultivate talents with innovation spirit and practice ability.

\section{REFERENCES}

[1] Li Guicheng. Discussion on the Teaching Reform of Calculations. Higher Education of Sciences, 2008 ( 7 ).

[2] Li Dan, Huang Youxia. Discussion on Applying Mathematical Modeling to the Learning of Mathematics. Education Reform of [J]., 2010 ( 35 ).

[3] Deng Jianzhong, Liu ZhiXing. Computational Method[M]. Xi'an Jiao Tong University press, 2002,6.

[4] Qu Wen. Some Ideas About Teaching Numerical Computational Method [J]. Computer Teaching and Educational Information, 2009 ( 4 ). 